\title{
Comparative Characteristics of Gold-Gold and Gold-Silver Nanogaps Probed by Raman Scattering Spectroscopy of 1,4-Phenylenediisocyanide ${ }^{\dagger}$
}

\author{
Kwan Kim, ${ }^{*}$ Jeong-Yong Choi, Dongha Shin, Hyang Bong Lee, and Kuan Soo Shin ${ }^{*}$ * \\ Department of Chemistry, Seoul National University, Seoul 151-742, Korea*E-mail: kwankim@snu.ac.kr \\ \$Department of Chemistry, Soongsil University, Seoul 156-743, Korea.*E-mail: kshin@ssu.ac.kr \\ Received March 5, 2011, Accepted March 14, 2011
}

\begin{abstract}
A nanogap formed by a metal nanoparticle and a flat metal substrate is one kind of "hot site" for surface-enhanced Raman scattering (SERS). The characteristics of a typical nanogap formed by a planar Au and either an Au and $\mathrm{Ag}$ nanoparticle have been well studied using 4-aminobenzenethiol (4-ABT) as a probe. 4-ABT is, however, an unusual molecule in the sense that its SERS spectral feature is dependent not only on the kinds of SERS substrates but also on the measurement conditions; thus further characterization is required using other adsorbate molecules such as 1,4-phenylenediisocyanide (1,4-PDI). In fact, no Raman signal was observable when 1,4-PDI was selfassembled on a flat Au substrate, but a distinct spectrum was obtained when $60 \mathrm{~nm}$-sized Au or Ag nanoparticles were adsorbed on the pendent $-\mathrm{NC}$ groups of 1,4-PDI. This is definitely due to the electromagnetic coupling between the localized surface plasmon of $\mathrm{Au}$ or $\mathrm{Ag}$ nanoparticle with the surface plasmon polariton of the planar Au substrate, allowing an intense electric field to be induced in the gap between them. A higher Raman signal was observed when Ag nanoparticles were attached to 1,4-PDI, irrespective of the excitation wavelength, and especially the highest Raman signal was measured at the $632.8 \mathrm{~nm}$ excitation (with the enhancement factor on the order of $\sim 10^{3}$ ), followed by the excitation at 568 and $514.5 \mathrm{~nm}$, in agreement with the finite-difference timedomain calculation. From a separate potential-dependent SERS study, the voltage applied to the planar Au appeared to be transmitted without loss to the $\mathrm{Au}$ or $\mathrm{Ag}$ nanoparticles, and from the study of the effect of volatile organics, the voltage transmission from $\mathrm{Au}$ or $\mathrm{Ag}$ nanoparticles to the planar Au also appeared as equally probable to that from the planar $\mathrm{Au}$ to the $\mathrm{Au}$ or $\mathrm{Ag}$ nanoparticles in a nanogap electrode. The response of the $\mathrm{Au}-\mathrm{Ag}$ nanogap to the external stimuli was, however, not the same as that of the Au-Au nanogap.
\end{abstract}

Key Words : Surface-enhanced raman scattering, 1,4-Phenylenediisocyanide, Au-Ag nanogap, Au-Au nanogap, Volatile organic chemical

\section{Introduction}

Noble metallic nanostructures exhibit a phenomenon known as surface-enhanced Raman scattering (SERS) in which the scattering cross sections are enhanced up to $10^{14}-10^{15}$ times for molecules adsorbed thereon, allowing even single-molecule spectroscopy possible. ${ }^{1-5}$ Accordingly, ever since its discovery in the middle of 1970s SERS has found applications in many areas of chemistry, including chemical analysis, corrosion, lubrication, and heterogeneous catalysis. ${ }^{6-10}$ The phenomenon of SERS is thus practical and highly attractive, but surprisingly the origin of SERS has not yet been clearly clarified, although electromagnetic and chemical enhancement mechanisms are definitely responsible for the occurrence of SERS. ${ }^{2}$ In conjunction with single-molecule SERS, an electromagnetic "hot spot" has been predicted to exist in large fractal aggregates of $\mathrm{Ag}$ particles. ${ }^{11,12}$ The junction of two aggregated Ag nanoparticles has also been claimed to be the "hot site" for SERS. ${ }^{13}$ We recently recognized that highly intense Raman spectra could be obtained when 4-aminobenzenethiol (4-ABT) was sandwiched between planar $\mathrm{Au}$ and nanosized $\mathrm{Au}$ or $\mathrm{Ag}$ particles, as

"This paper is dedicated to Professor Eun Lee on the occasion of his honourable retirement. labeled by Au(Ag)@4-ABT/Au(flat). ${ }^{14-16}$ The SERS signal must have derived from the electromagnetic coupling of the localized surface plasmon of $\mathrm{Au}(\mathrm{Ag})$ nanoparticles with the surface plasmon polariton of the underneath Au metal.

4-ABT, used in the characterization of the nanogap formed by a planar $\mathrm{Au}$ and either an $\mathrm{Au}$ or $\mathrm{Ag}$ nanoparticle, is an unusual molecule in the sense that its SERS spectral feature is dependent not only on the kinds of SERS substrates but also on the measurement conditions. In the normal Raman spectrum, peaks assignable to totally symmetric vibrations are exclusively observed, but non-a $\mathrm{a}_{1}$ type peaks are additionally identified in the SERS spectrum. Considering the potential and excitation wavelength dependence, the bands have been assumed in the past 15 years to belong to $b_{2}$ symmetry vibrations of 4-ABT, arising from the metal-to-adsorbate or the vice versa charge transfer transition. ${ }^{17-19}$ Very recently, however, there is a debate that the bands would be due to the $A_{g}$ modes of dimercaptoazobenzene supposedly produced from 4-ABT via a catalytic coupling reaction on metal substrates. ${ }^{20-22}$ Owing to this kind of conflict, we worry that 4-ABT may not be a proper molecule to characterize the "hot sites" for SERS. Other adsorbate molecule must then be sought for better characterization of the naogaps formed by planar $\mathrm{Au}$ and $\mathrm{Au}$ or Ag nanoparticles. 
Organic diisocyanide such as 1,4-phenylenediisocyanide (1,4-PDI) is known to adsorb on gold via only one of its two isocyanide groups. ${ }^{23}$ The other isocyanide group is pendent with respect to the gold substrate so that new $\mathrm{Au}$ or $\mathrm{Ag}$ nanoparticles can further bind onto it forming a sandwich-type molecular nanostructure. In addition to a "hot site" for SERS, such a nanogap electrode is attractive in regard to molecular electronics, since an organic diisocyanide could function as a molecular wire. ${ }^{24}$ The main issue therein is how effectively a voltage applied to the gold substrate can be transmitted to the $\mathrm{Au}$ or Ag nanoparticles and vice versa. ${ }^{25}$ If the voltage transmission is efficient, any unbalanced electronic charge will readily be equilibrated between the Au or Ag nanoparticle and the planar Au substrate. Another interesting point of SERS of organic isocyanides is associated with the susceptibility of the NC stretching frequency in response to external disturbance such as a change in potential and an exposure to volatile organic chemicals (VOCs). For instance, the NC stretching band is either blue- or red-shifted, depending on the electron withdrawing or donating property of VOCs exposed to the isocyanide-adsorbed SERS active substrate. ${ }^{26}$

In conjunction with above implications, the primary purpose of this work is to characterize in more detail the electromagnetic field enhancement at the nanogap formed by a flat $\mathrm{Au}$ and an $\mathrm{Au}$ or $\mathrm{Ag}$ nanoparticle by virtue of the Raman scattering of 1,4-PDI. It was also attempted to understand the observed difference between the $\mathrm{Au}-\mathrm{Au}$ and $\mathrm{Au}-\mathrm{Ag}$ nanogaps by means of a three-dimensional finite-difference time-domain (3-D FDTD) calculation. The secondary purpose of this work is to find out whether the NC peak shift occurring by VOCs is correlated with their electron withdrawing and electron donating property, as predicted by ab initio calculation. The tertiary purpose of this work is to make sure whether the excess surface charge supplied onto $\mathrm{Au}$ or $\mathrm{Ag}$ nanoparticles by VOCs is transmitted well to the planar Au substrate. In this regard, we also measured the potential-dependent SERS spectra by varying the potential of the $\mathrm{Au}$ (flat) substrate, and carefully examined the variation of the position, shape, and width of the NC stretching band of 1,4-PDI. Altogether, the SERS of 1,4-PDI is proven to be an invaluable tool to assess not only the nanogaps that are able to amplify the electromagnetic field but also even the molecular wires that are capable of transporting charge in molecular electronics.

\section{Experimental Section}

Hydrogen tetrachloroaurate $\left(\mathrm{HAuCl}_{4}\right)$, silver nitrate $\left(\mathrm{AgNO}_{3}\right)$, Au wire (diameter $=0.25 \mathrm{~mm}, 99.99 \%$ ), trisodium citrate, and 1,4-PDI were purchased from Aldrich, and used as received. Other chemicals, unless specified, were reagent-grade. Highly purified water, with a resistivity greater than $18.0 \mathrm{M} \Omega \cdot \mathrm{cm}$ (Millipore Milli-Q System), was used in preparing aqueous solutions.

Gold and silver sols were prepared by following the Lee and Meisel method. ${ }^{27}$ For Au sol, $50 \mathrm{~mL}$ of $0.25 \mathrm{mM}$ aqueous solution of $\mathrm{HAuCl}_{4}$ was heated to boiling, and then $0.4 \mathrm{~mL}$ of $1 \%(\mathrm{w} / \mathrm{v})$ aqueous solution of sodium citrate was added. The solution was kept boiling for $30 \mathrm{~min}$. For $\mathrm{Ag}$ sol, $100 \mathrm{~mL}$ of $1 \mathrm{mM}$ aqueous solution of $\mathrm{AgNO}_{3}$ was heated to boiling, and then $2 \mathrm{~mL}$ of $1 \%(\mathrm{w} / \mathrm{v})$ aqueous solution of sodium citrate was added. The solution was kept boiling for $30 \mathrm{~min}$. According to transmission electron microscopy (TEM) analyses, both the Au and Ag nanoparticles had an average diameter of $\sim 60 \mathrm{~nm}$. On the other hand, the surface plasmon absorption bands were identified distinctly at 545 and $435 \mathrm{~nm}$ in the UV-visible (UV-vis) spectra of Au and Ag sols, respectively. The particle concentration was adjusted to be the same $(0.04 \mathrm{nM})$ for both sols.

A macroscopically smooth Au substrate was prepared by resistive evaporation of titanium and gold at $1 \times 10^{-6}$ Torr onto a freshly cleaved mica sheet. After deposition of approximately $200 \mathrm{~nm}$ of gold, the evaporator was backfilled with nitrogen. Separately, an Au wire was flame annealed to obtain a flat Au substrate. The self-assembly of 1,4-PDI onto these Au substrates was conducted in $20 \mathrm{mM}$ ethanolic solution overnight. After washing with ethanol, the 1,4-PDI-adsorbed $\mathrm{Au}$ substrates were soaked in $\mathrm{Au}$ or $\mathrm{Ag}$ sol for $1 \mathrm{~h}$. The number of Au and Ag nanoparticles attached to 1,4-PDI were counted from field emission scanning electron microscopy (FE-SEM) images. The nanogap system fabricated on a vacuum evaporated Au film was subjected to Raman spectral measurements, but under spinning to average out any inhomogeneous distribution of $\mathrm{Au}$ and $\mathrm{Ag}$ nanoparticles. On the other hand, the nanogap system fabricated using an annealed $\mathrm{Au}$ wire was subjected to Raman spectral measurements, either as prepared or after soaking in electrolytic solution for potential-dependent SERS, or as a substrate put in a glass capillary exposed to VOCs.

The TEM images of the as-prepared Au and Ag sols were acquired using a JEM-200CX transmission electron microscope at $160 \mathrm{kV}$. The FE-SEM images were obtained with a JSM$6700 \mathrm{~F}$ field emission electron microscope operated at $5 \mathrm{kV}$. UV-vis spectra were obtained with a SINCO S-4100 UV-vis absorption spectrometer. The flow of organic vapors through a capillary tube was controlled using a Sage Instruments Model 341 syringe pump. Zeta potential measurement was obtained on a Zetasizer $3000 \mathrm{HS}$ (Malvern Instruments, UK) at $25^{\circ} \mathrm{C}$, using a Zetasizer 3000 (Advanced) Zeta mode v1.61 software for data acquisition. Raman spectra were obtained using a Renishaw Raman system Model 2000 spectrometer equipped with an integral microscope (Olympus BH2-UMA). The 514.5 $\mathrm{nm}$ line from a $20 \mathrm{~mW} \mathrm{Ar}^{+}$laser (Melles-Griot Model 351MA520) or the $568 \mathrm{~nm}$ line from a $20 \mathrm{~mW} \mathrm{Ar} / \mathrm{Kr}^{+}$laser (Melles-Griot Model 35KAP431) or the $632.8 \mathrm{~nm}$ line from a $17 \mathrm{~mW} \mathrm{He} / \mathrm{Ne}$ laser (Spectra Physics Model 127) were used as the excitation source. Raman scattering was detected over a $180^{\circ}$ range with a Peltier cooled $\left(-70{ }^{\circ} \mathrm{C}\right)$ charged-coupled device $(\mathrm{CCD})$ camera $(400 \times 600$ pixels $)$. The laser beam was focused onto a spot approximately $\sim 1 \mu \mathrm{m}$ in diameter with an objective microscope with magnification of the order of $20 \times$. The data acquisition time was usually $30 \mathrm{~s}$. The holographic grating (1800 grooves $/ \mathrm{mm})$ and the slit allowed the spectral resolution to be $1 \mathrm{~cm}^{-1}$. The Raman band of a silicon wafer at 
$520 \mathrm{~cm}^{-1}$ was used to calibrate the spectrometer, and the accuracy of the spectral measurement was estimated to be better than $1 \mathrm{~cm}^{-1}$. The potential of the electrochemical cell used for Raman spectral measurement was controlled by using a $\mathrm{CH}$ Instruments model $660 \mathrm{~A}$ potentiostat, which employed $\mathrm{CHI}$ $660 \mathrm{~A}$ electrochemical analyzer software (version 2.03) running on an IBM-compatible PC. All potentials are reported with respect to a saturated $\mathrm{Ag} / \mathrm{AgCl}$ electrode.

3-D FDTD electrodynamics simulation ${ }^{28,29}$ was carried out with FDTD solutions software (version 7.0.1) provided by Lumerical Solutions, Inc. A nanostructure composed of an $\mathrm{Au}$ or Ag nanoparticle and a flat gold surface was modeled as a single $\mathrm{Au}$ or Ag sphere $(60 \mathrm{~nm})$ laid on a cubical gold substrate with dimensions of $400 \mathrm{~nm} \times 400 \mathrm{~nm} \times 150 \mathrm{~nm}$. The gap between the sphere and the cuboid was fixed to be $1 \mathrm{~nm}$. The dielectric constants of the silver and gold were taken from the source program. The propagation directions of plane waves (514.5, 568, and $632.8 \mathrm{~nm}$ wavelength) were chosen to be along the $\mathrm{x}$ - or $\mathrm{z}$-axis. In each case, the electric field was assumed to be polarized along the z-axis and y-axis, respectively. Boundary conditions were imposed by means of the perfectly matched layer method. After the computation of the local electric field, the field intensity was evaluated for each mesh by integration and finally compared with the enhancement factor $(\mathrm{EF})$ values estimated from the measured Raman spectra.

\section{Results and Discussion}

Figures 1(a) and 1(b) show the TEM images of Au and Ag sol particles, respectively. Most of the nanoparticles are of a spherical shape, although faceted particles are also observed especially in Ag sol. According to the histograms shown in Figure 1(c), the mean diameters of the $\mathrm{Au}$ and $\mathrm{Ag}$ particles are $59.4 \pm 9.9$ and $56.9 \pm 5.3 \mathrm{~nm}$, respectively. As shown in Figure 1(d), the $\mathrm{Au}$ and $\mathrm{Ag}$ sols exhibited very distinct surface plasmon absorption bands centered at 545 and $435 \mathrm{~nm}$, respectively. The zeta potential measurements indicated that both the $\mathrm{Au}$ and $\mathrm{Ag}$ nanoparticles were negatively charged, i.e., -46.9 and $-47.9 \mathrm{mV}$, respectively, due to the deprotonation of the citrate moiety. Due to the negative surface charge, there exists substantial electrostatic repulsion between particles, which hinders their close-packed adsorption on 1,4-PDI on a flat $\mathrm{Au}^{30}{ }^{30}$ According to the FE-SEM images shown in Figures 1(e) and 1(f), the surface coverages of $\mathrm{Au}$ and $\mathrm{Ag}$ nanoparticles after adsorption on 1,4-PDI on a flat $\mathrm{Au}$ are determined to be 3.1 and 5.3 particles per $\mu \mathrm{m}^{2}$, respectively.

As one would expect, Raman signal was not detectable at all when 1,4-PDI was adsorbed onto the flat $\mathrm{Au}$ surface. However, Raman spectra are distinctly observed as $\mathrm{Au}$ or $\mathrm{Ag}$ nanoparticles are adsorbed onto the pendent $\mathrm{NC}$ group, owing to the electromagnetic coupling between the localized surface plasmon of $\mathrm{Au}$ or $\mathrm{Ag}$ nanoparticles and the surface plasmon polariton of the flat $\mathrm{Au}$ substrate. ${ }^{31-33}$ This can be evident from the spectra shown in Figures 2(a) and 2(b), taken using three different excitation wavelengths after attaching $\mathrm{Au}$ or $\mathrm{Ag}$ nanoparticles, respectively, onto 1,4-PDI on a vacuum evaporated Au substrate: these nanostructures are labeled either Au@1,4-

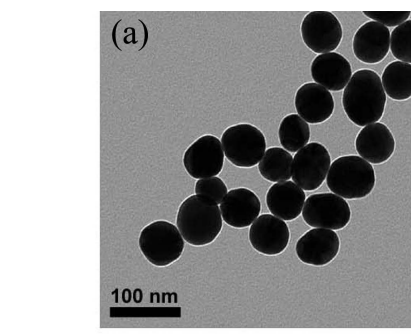

(b)
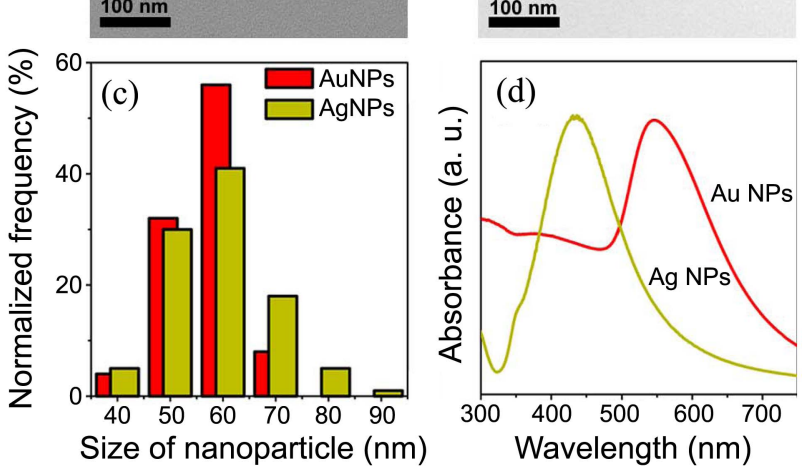

(d)
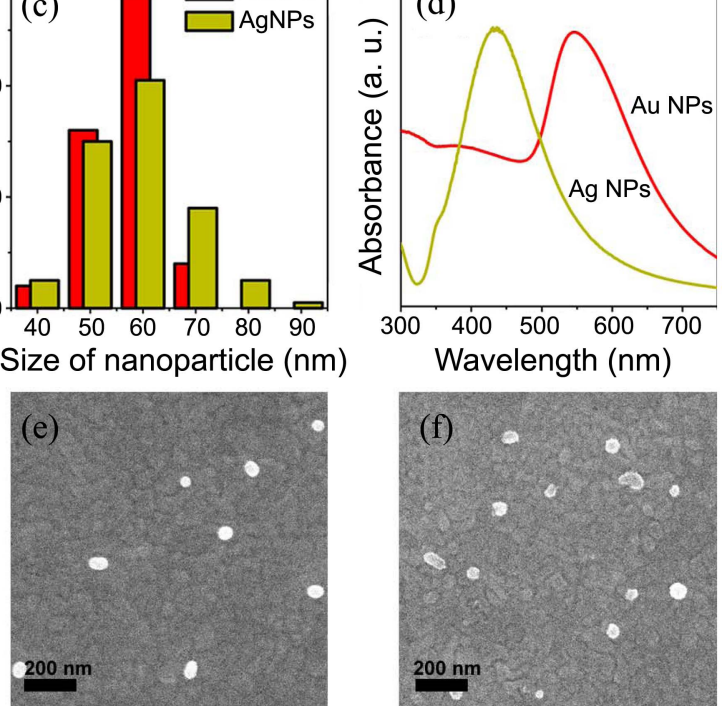

Wavelength $(\mathrm{nm})$

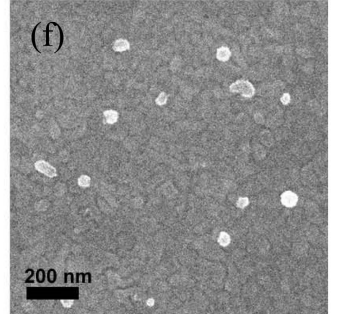

Figure 1. TEM images of (a) Au and (b) Ag sol particles, and (c) their size histograms and (d) their UV-vis absorption spectra taken in colloid state. FE-SEM images taken for (e) Au@1,4-PDI/Au (vacuum) and (f) Ag@1,4-PDI/Au(vacuum). See text. (a)
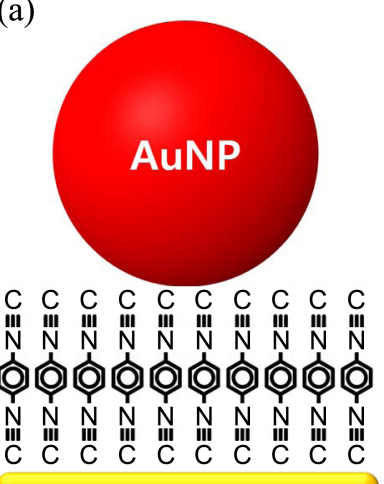

Au film (b)

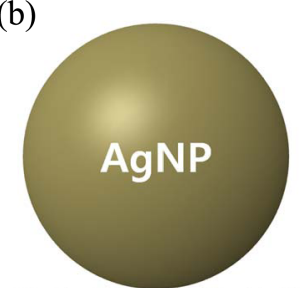

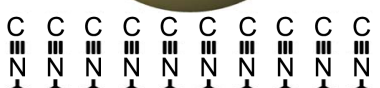

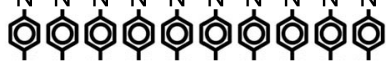

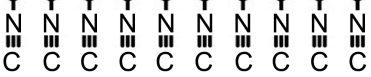

Au film

Scheme 1. Schematic diagram of a nanogap, formed by a planar $\mathrm{Au}$ substrate and (a) an $\mathrm{Au}$ or (b) an Ag nanoparticle, in which a probe molecule, 1,4-PDI, is sandwiched in the nanogaps.

PDI/Au(vacuum) or Ag@1,4-PDI/Au(vacuum) (See Scheme 1). As mentioned in the Experimental section, these Raman spectra were taken while spinning the samples at $3000 \mathrm{rpm}$ to minimize any effect due to inhomogeneous distribution of the $\mathrm{Au}$ and $\mathrm{Ag}$ nanoparticles. Further, the spectra were represented after normalizing with respect to the number of surface coverage of $\mathrm{Au}$ and $\mathrm{Ag}$ nanoparticles, as well as the absolute intensity of a silicon wafer at $520 \mathrm{~cm}^{-1}$ at a specified excitation 

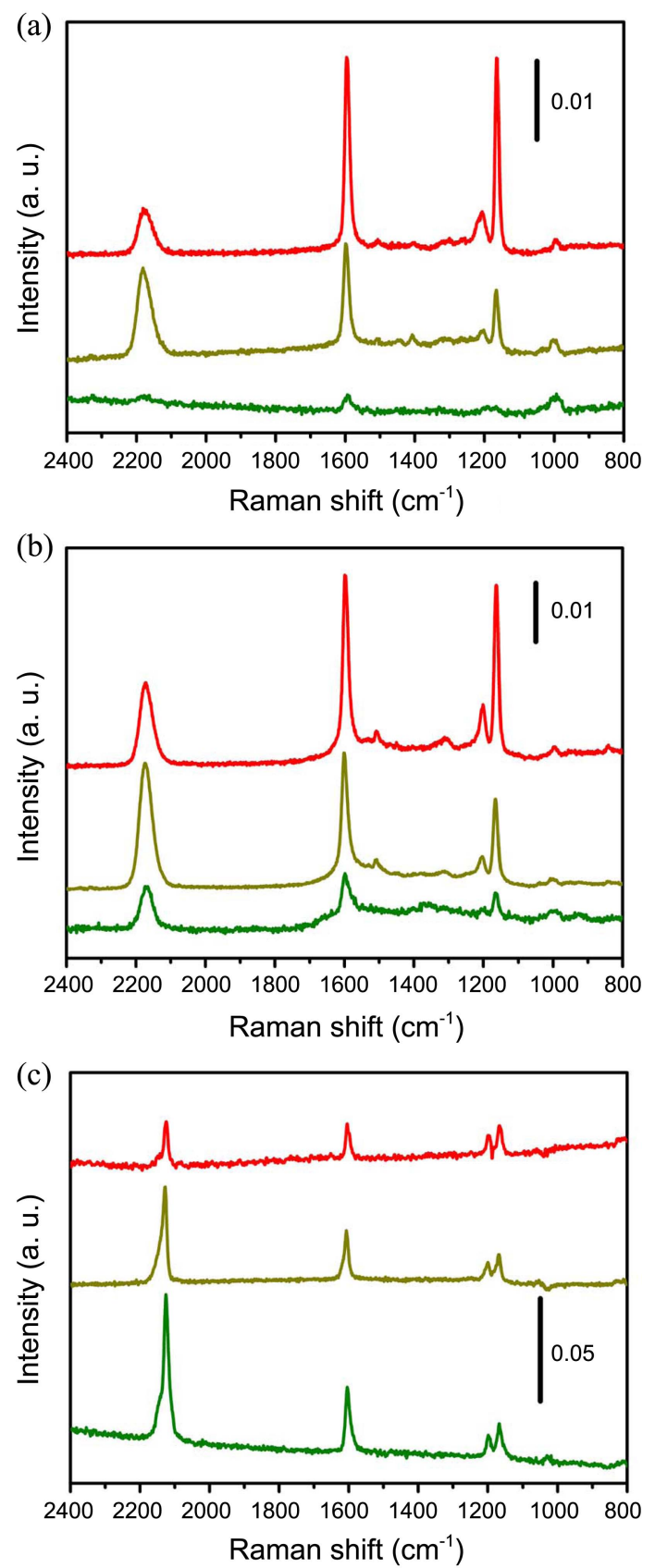

Figure 2. Raman spectra taken using 514.5, 568, and $632.8 \mathrm{~nm}$ radiation (from bottom to top) as the excitation source for (a) $\mathrm{Au} @ 1,4-$ $\mathrm{PDI} / \mathrm{Au}$ (vacuum) and (b) $\mathrm{Ag} @ 1,4-\mathrm{PDI} / \mathrm{Au}$ (vacuum) nanogap systems. (c) NR spectrum of $0.1 \mathrm{M}$ 1,4-PDI in ethanol taken using the same lasers as above.

wavelength. For a better analysis of these gap mode spectra, the normal Raman (NR) spectra of neat 1,4-PDI taken at three different excitation wavelengths are also shown in Figure 2(c). The NR spectral pattern was little affected by excitation wavelength, although a more intense spectrum was measured at a lower excitation wavelength.

The bands at $2126,1605,1198$, and $1167 \mathrm{~cm}^{-1}$ in the NR spectrum of 1,4-PDI can be assigned to the NC stretching, ring $8 \mathrm{a}$, ring $7 \mathrm{a}$, and ring 9a modes of 1,4-PDI, respectively. ${ }^{34}$ In the gap mode spectra in Figure 2(a), their counter bands are observed at $2177,1597,1204,1165 \mathrm{~cm}^{-1}$, respectively, while in Figure 2(b) at 2173, 1598, 1204, and $1163 \mathrm{~cm}^{-1}$, respectively. There is significant difference in the peak position of the NC stretching band between the NR and gap mode spectra, although little differences are observed for the ring modes. The bandwidths of the NC stretching bands are also substantially broader in the gap mode spectra than in the NR spectrum, while the bandwidths of the ring modes are comparable to one another. ${ }^{35}$ These spectral differences are due to the adsorption of 1,4-PDI exclusively via the two -NC groups to Au substrate and $\mathrm{Au}$ or $\mathrm{Ag}$ nanoparticles. It is known that the lone pair electrons of the -NC: group are antibonding with respect to the $\mathrm{NC}$ bond. ${ }^{36}$ Accordingly, the donation of the carbon lone pair electrons to $\mathrm{Au}$ or $\mathrm{Ag}$ leads to stronger $\mathrm{NC}$ bonds, resulting in the blue-shift of the NC stretching vibration. The blue shift in Figure 2(a) is slightly larger than that in Figure 2(b), suggesting that the electron donation capability of the isocyanide group to gold is somewhat greater than that to silver. Further, the NC stretching band in Figure 2(b) is broader and more asymmetric than that in Figure 2(a) due to one -NC group of 1,4PDI being bound to Au but the other -NC group being bound to $\mathrm{Ag}$ in the $\mathrm{Ag} @ 1,4-\mathrm{PDI} / \mathrm{Au}$ (vacuum) system.

Based on the assignment of the NC stretching bands, we have subsequently estimated the EF values for all gap mode spectra shown in Figures 2(a) and 2(b). At first, the number of 1,4-PDI molecules illuminated by the laser light used in obtaining the NR spectra were estimated by taking account of the facts that the size of the laser spot is $\sim 1 \mu \mathrm{m}$ and its penetration depth into 1,4-PDI is $\sim 40 \mu \mathrm{m}$ (since Raman signals reached a steady state when the thickness of an organic film became greater than $40 \mu \mathrm{m}){ }^{21}$ Assuming that the sampling volume is well represented by the product of the laser spot size and its penetration depth, the number of 1,4-PDI molecules illuminated is calculated to be $1.9 \times 10^{9}$ (i.e., $3.1 \times 10^{-15} \mathrm{~mol}$ ). We subsequently estimated the number of 1,4-PDI molecules that could be present on the planar Au substrate. Assuming that each 1,4-PDI molecule occupies an area of $\sim 0.20 \mathrm{~nm}^{2}$ at the full coverage limit on $\mathrm{Au}$, as similarly to $p$-disubstituted benzene derivatives such as 4 -aminobenzenthiolate, ${ }^{37}$ the number of 1,4-PDI molecules that can be illuminated by a $1 \mu \mathrm{m}$ sized laser beam is calculated to be $3.9 \times 10^{6}$ (i.e., $6.5 \times 10^{-18}$ mol). The ratio of the numbers of 1,4-PDI molecules illuminated in NR and SERS spectral measurements would then amount to $4.8 \times 10^{2}$ (i.e., $1.9 \times 10^{9} / 3.9 \times 10^{6}$ ). The apparent EF values may then be obtained by dividing the latter value with the intensity ratio of the NC stretching band of 1,4-PDI in NR and SERS spectra. Dividing further the apparent EF values with the averaged number of $\mathrm{Au}$ or $\mathrm{Ag}$ nanoparticles per $\mu \mathrm{m}^{2}$ on 1,4-PDI on a planar Au should result in EF values. The EF values obtained in this way are plotted in Figure 3(a) as a function of the excitation wavelength for both the Au@1,4PDI/Au(vacuum) and Ag@1,4-PDI/Au(vacuum) systems. For both systems, the more intense Raman signal is obtained with an increase in the excitation wavelength.

It is evident in Figure 3(a) that higher EF values are observed, irrespective of the excitation wavelength, when $\mathrm{Ag}$ nanoparticles are adsorbed on 1,4-PDI on a flat $\mathrm{Au}$ substrate than are Au nanoparticles. When Au nanoparticles 

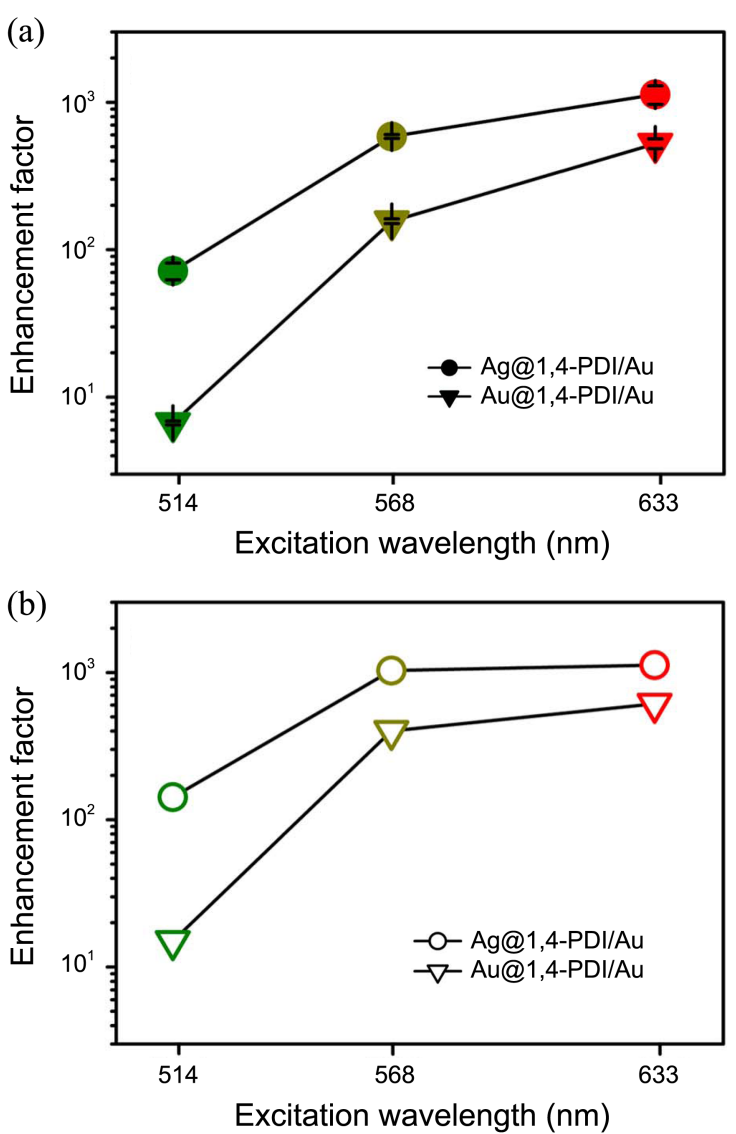

Figure 3. (a) Experimental and (b) theoretical EFs determined for the $\mathrm{NC}$ stretching band of 1,4-PDI in Au@1,4-PDI/Au(vacuum) and $\mathrm{Ag} @ 1,4-\mathrm{PDI} / \mathrm{Au}(\mathrm{vacuum})$ drawn as a function of the excitation wavelength. Experimental EFs were determined by referring to the SERS spectra shown in Figure 2. Theoretical EFs were predicted using the 3-D FDTD method by taking into account the portions of the perpendicular and parallel polarizations in an actual experimental condition. See text.

are laid on 1,4-PDI, a quite intense Raman signal is detected with 568 and $632.8 \mathrm{~nm}$ excitation, but the EF at $514.5 \mathrm{~nm}$ excitation is more than two orders of magnitude smaller than that at $632.8 \mathrm{~nm}$ excitation. Even when Ag nanoparticles are laid on 1,4-PDI, the EF at $514.5 \mathrm{~nm}$ excitation is not great, but only one order of magnitude smaller than that at 632.8 $\mathrm{nm}$ excitation. Anyhow, the EF at $632.8 \mathrm{~nm}$ excitation was even greater when an Ag nanoparticle was laid on 1,4-PDI than was an Au nanoparticle. The Au-Ag gaps are thus more SERS active than the Au-Au gaps in all excitation wavelengths. To see whether this is acceptable, we have carried out 3-D FDTD simulations.

As described in the Experimental Section, a nanostructure was modeled in this simulation to be composed of a single gold or silver sphere of diameter $60 \mathrm{~nm}$ laid on a cubical gold substrate of dimensions $400 \mathrm{~nm} \times 400 \mathrm{~nm} \times 150 \mathrm{~nm}$. The gap distance between the $\mathrm{Au}$ or $\mathrm{Ag}$ sphere and $\mathrm{Au}$ cuboid was fixed to be $1 \mathrm{~nm}$. Figure 4 shows the FDTD result obtained under the irradiation of $632.8 \mathrm{~nm}$ light on the $\mathrm{Ag}$-Au nano gap. The intensity of the induced electric field was extremely sensitive to the polarization direction of the incident radiation. Especially a strong electric field was induced at the gap when
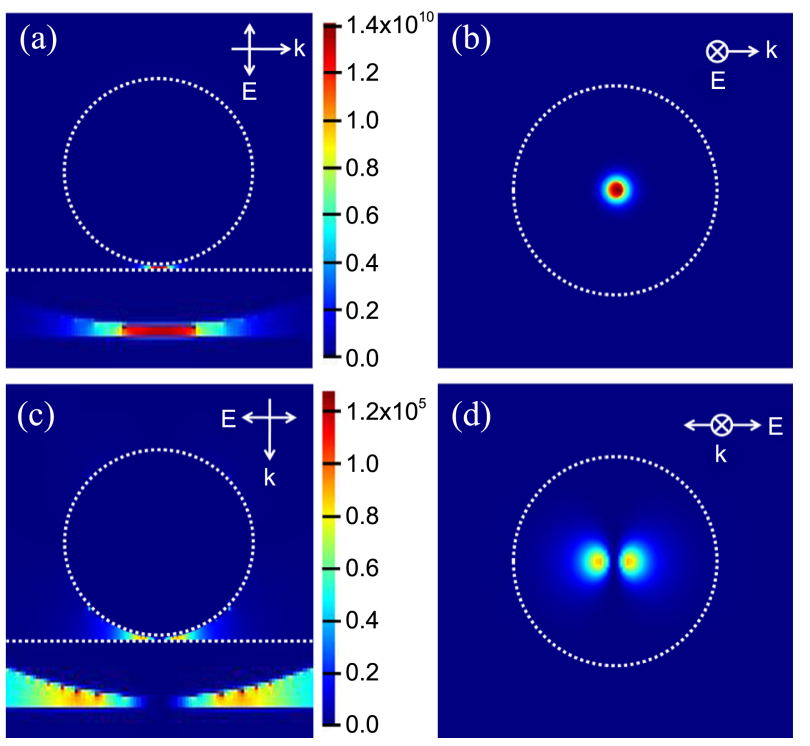

Figure 4. Intensity distribution $\left(\left|E / E_{0}\right|^{4}\right)$ of induced local electric field $E$ relative to the excitation field $E_{0}$ near $60-\mathrm{nm}$ sized $\mathrm{Ag}$ sphere and Au cuboid, calculated by the 3-D FDTD method in a condition that the electric field (632.8 nm radiation) is directed perpendicular ( $a$ and $b$ ) or parallel ( $c$ and d) to the surface of the $\mathrm{Au}$ cuboid. Insets are the magnified images of the gap sites.

a perpendicularly polarized light was used as the incident light. Hence, taking account of the fact that the Raman scattering enhancement could be represented as $\left|E / E_{\mathrm{o}}\right|^{4}(E$ and $E_{\mathrm{o}}$ are the local and input fields, respectively), ${ }^{38}$ the maximum EF value could be as large as $1.4 \times 10^{10}$ in the perpendicular polarization (See Figures 4(a) and 4(b)), while the maximum in response to the parallel-polarized light would be at most $1.3 \times 10^{5}$ (See Figures 4(c) and 4(d)). Anyhow, for a better comparison with the experimental EF values, we have taken into account the arrangement of the Raman laser used in this work: We have estimated the percentage of a perpendicularly polarized beam by referring that the diameter of the laser beam was $7 \mathrm{~mm}$ (before focusing) and the focal length of the object lens was $9 \mathrm{~mm}$. The theoretical EF values thus computed by weighting the contribution of perpendicular and parallel polarized light are finally represented in Figure 3(b). It is very noteworthy that the theoretical excitation wavelength dependence is largely comparable to the experimental data.

Using separately prepared $\mathrm{Au}-\mathrm{Au}$ and $\mathrm{Ag}-\mathrm{Au}$ nanogap systems fabricated using an annealed Au wire, i.e., Au@1,4PDI/Au(wire) and Ag@1,4-PDI/Au(wire) electrodes, we subsequently measured the potential-dependent SERS spectra in $0.1 \mathrm{M} \mathrm{NaClO}_{4}$ aqueous solutions, using the $632.8 \mathrm{~nm}$ radiation as the excitation source. The SERS spectra measured were reproducible in the potential region of +0.2 to $-0.6 \mathrm{~V}$ vs a saturated $\mathrm{Ag} / \mathrm{AgCl}$ reference electrode. As shown in Figures 5(a) and 5(b) for $\mathrm{Au}-\mathrm{Au}$ and $\mathrm{Ag}-\mathrm{Au}$ nanogap electrodes, respectively, the peak positions as well as the bandwidths of the ring modes were not subjected to change following the potential variation. The relative peak intensities of the ring modes were also invariant with respect to the potential variation. Nonetheless, the NC stretching peak was gradually blue-shifted following an increase in the surface potential 

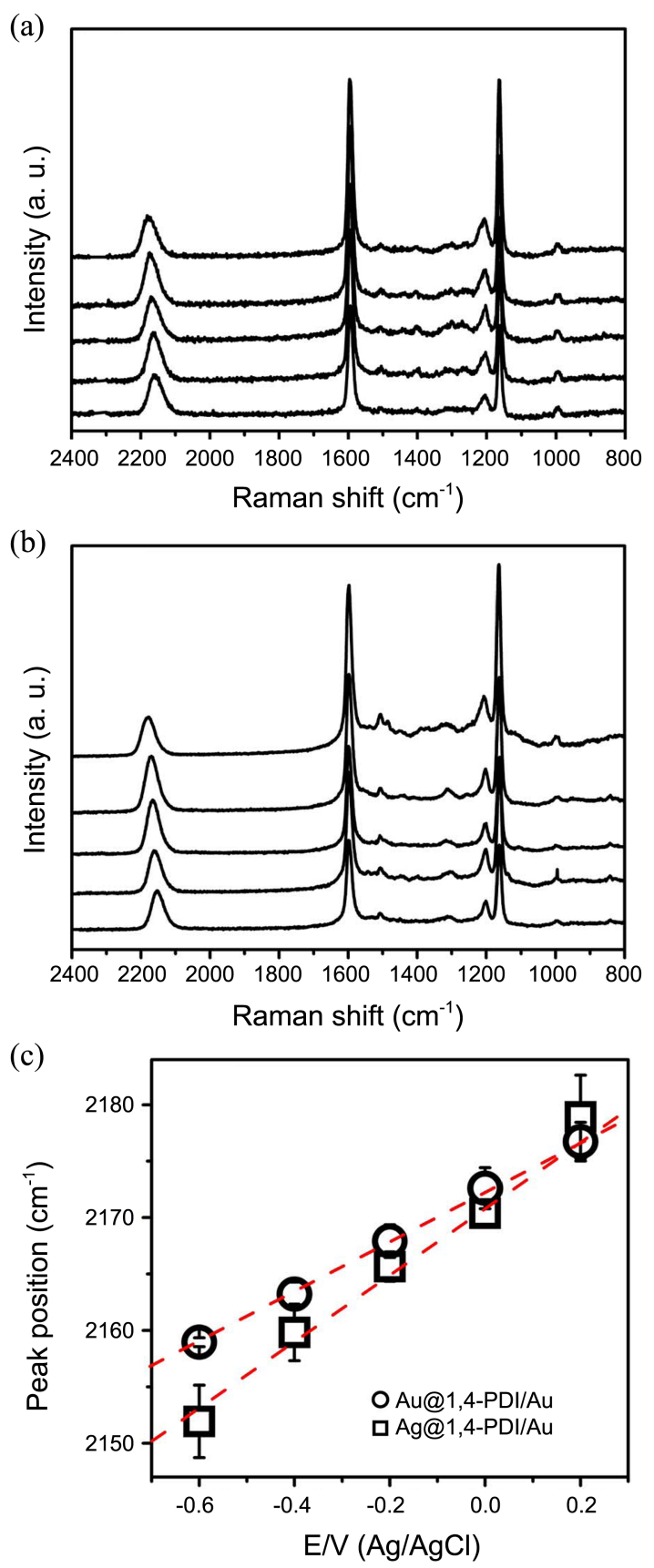

Figure 5. Potential dependent SERS spectra measured using (a) $\mathrm{Au} @ 1,4-\mathrm{PDI} / \mathrm{Au}$ (wire) and (b) $\mathrm{Ag} @ 1,4-\mathrm{PDI} / \mathrm{Au}$ (wire) as a working electrode in $0.1 \mathrm{M} \mathrm{NaClO}_{4}$ with $632.8 \mathrm{~nm}$ radiation as the excitation source. (c) Positions of the NC stretching peaks of 1,4-PDI in (a) and (b) drawn versus the applied potential.

and vice versa. As the potential is made more positive, there is increased $\sigma$ donation from the $\mathrm{C}$ atom to $\mathrm{Au}(\mathrm{Ag})$, resulting in a greater shift of electron density from the $\mathrm{N}$ atom into the $\mathrm{NC}$ bond, and as a consequence, both the bond order and the vibrational frequency are increased. ${ }^{39}$ The opposite will take place when the potential is made more negative. Nonetheless, the shape of the NC stretching band is independent of the potential variation. This is not unexpected since the measurement system is electrically closed. The pendent NC group is then located well inside the electrical double layer such as to feel the applied electric field as equally as the Au wire electrode. The voltage applied to the planar Au wire is transmitted without loss to the Au or Ag nanoparticles. Otherwise, we might have observed a very asymmetric $\mathrm{NC}$ stretching peak composed of two bands, one due to $\mathrm{NC}$ attached to the planar $\mathrm{Au}$ wire and the other due to $\mathrm{NC}$ attached to the $\mathrm{Au}$ or $\mathrm{Ag}$ nanoparticles. Anyhow, the NC stretching band is, naturally, slightly more asymmetric and also wider when 1,4-PDI is present in the Ag-Au nanogap than in the Au-Au nanogap. In this way, the NC stretching peaks were observed at 2177, $2171,2165,2159$, and $2153 \mathrm{~cm}^{-1}$ at $+0.2,0.0,-0.2,-0.4$, and $-0.6 \mathrm{~V}$, respectively, for the $\mathrm{Au}-\mathrm{Au}$ electrode, while at 2177 , 2172, 2168, 2163, and $2159 \mathrm{~cm}^{-1}$ for the Ag-Au electrode. As can be seen in Figure 5(c), the NC stretching peaks are thus determined to vary linearly with a slope of 22.3 and $29.6 \mathrm{~cm}^{-1}$ $\mathrm{V}^{-1}$ for the Au-Au and Ag-Au electrodes, respectively. The slope is slightly greater at the $\mathrm{Ag}-\mathrm{Au}$ electrode, suggesting that the $-\mathrm{NC}$ group bound to $\mathrm{Ag}$ must experience a stronger Stark effect ${ }^{40}$ in electrochemical environment, although the bonding effect would be greater when 1,4-PDI was bound to Au.

As another means to distinguish the two types of gaps, we have examined the response of the NC stretching vibration of 1,4-PDI under the flow of two typical VOCs, acetic acid and ammonia. ${ }^{41}$ Although only a negligible change was seen for the ring modes of 1,4-PDI, the NC stretching band has blueand red-shifted under the flow of acetic acid and ammonia, respectively. In specific, as shown in Figures 6(a) and 6(b), in the presence of acetic acid, the $\mathrm{NC}$ stretching peak was blueshifted by up to 8 and $3 \mathrm{~cm}^{-1}$, respectively, for the $\mathrm{Au}-\mathrm{Au}$ and Ag-Au nanogaps. On the other hand, as shown in Figures 6(c) and 6(d), in the presence of ammonia, the NC stretching peak was red-shifted by up to 9 and $4 \mathrm{~cm}^{-1}$, respectively, for the $\mathrm{Au}-\mathrm{Au}$ and $\mathrm{Ag}-\mathrm{Au}$ nanogaps. The amount of blue- and red-shift is obviously larger for the Au-Au nanogap than for the Ag-Au nanogap. This suggests that Au nanoparticles must be affected more by VOCs than Ag nanoparticles. The blueshift by acetic acid can be understood by assuming that electrons are transferred from $\mathrm{Au}$ or $\mathrm{Ag}$ nanoparticles to the carbonyl oxygen atom of acetic acid, ${ }^{42}$ as schematically drawn in Figure 6(e). In such circumstance, the surface potential of $\mathrm{Au}$ or Ag nanoparticles has to move in the positive direction, resulting in the blue-shift of the NC stretching band of 1,4-PDI. That is, as the $\mathrm{Au}$ or $\mathrm{Ag}$ nanoparticles are more positively charged, there must be an increased $\sigma$ donation from the $\mathrm{C}$ atom of the isocyanide group of 1,4-PDI to Au or Ag. Because the carbon lone-pair electrons have an antibonding character, the increased donation of these electrons to gold and silver should increase the strength of the $\mathrm{NC}$ bond, resulting in the blue-shift of the NC stretching mode. Conversely, the red-shift by ammonia can be understood by recalling that $\mathrm{NH}_{3}$ is a prototype molecule able to donate electrons to metal by adsorption, ${ }^{43}$ as schematically drawn in Figure 6(f). To test its feasibility, we have carried out a simple $a b$ initio quantum mechanical calculation.

At first, the binding energy and then the atomic polar tensor based charge population were computed for acetic acid and ammonia interacting with a single $\mathrm{Au}$ or $\mathrm{Ag}$ atom using the 

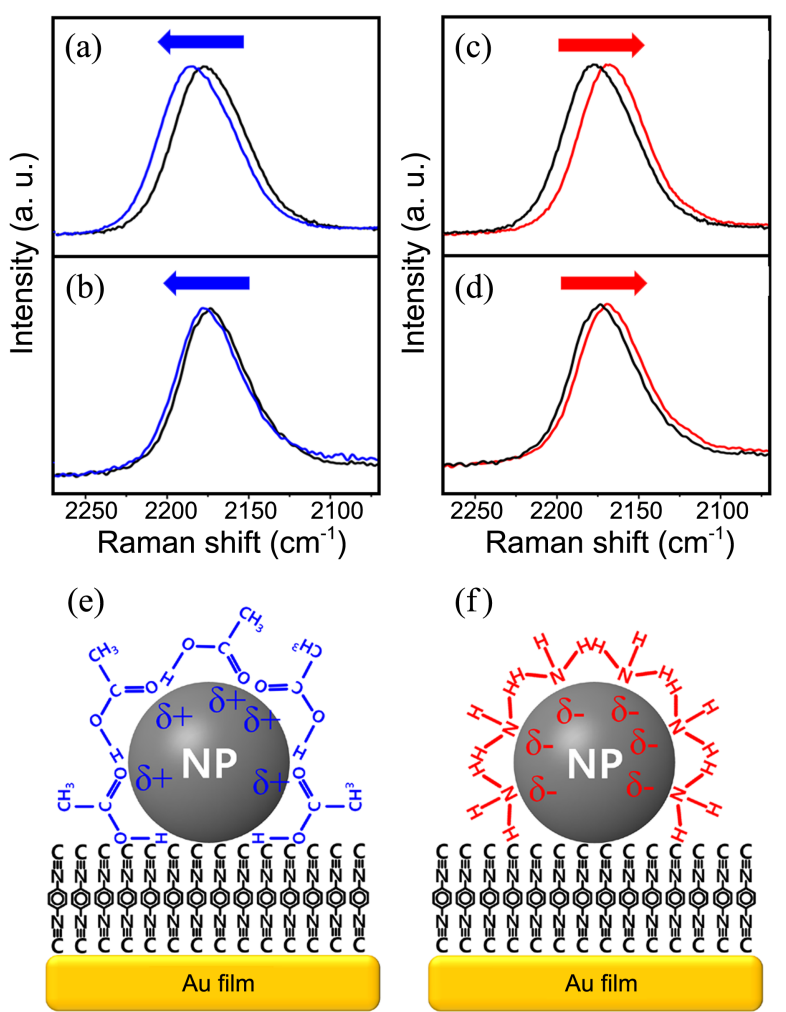

(f)

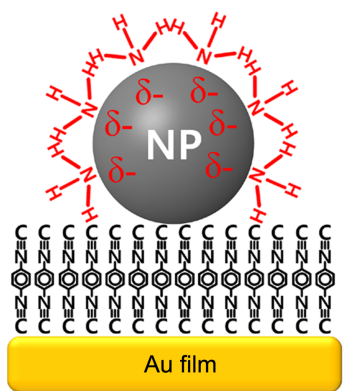

Figure 6. SERS spectra of 1,4-PDI taken under the flow of (a and b) acetic acid and (c and d) ammonia over Au@1,4-PDI/Au(wire) and $\mathrm{Ag} @ 1,4-\mathrm{PDI} / \mathrm{Au}$ (wire) put in a glass capillary, respectively: $632.8 \mathrm{~nm}$ radiation was used as the excitation source. Schematic diagrams showing the origin of (e) blue-shift by acetic acid in (a and $b$ ) and (f) red-shift by ammonia in (c and d).

Table 1. Binding energies of acetic acid and ammonia with single $\mathrm{Au}$ and $\mathrm{Ag}$ atoms and the accompanying changes in net charges of $\mathrm{Au}$ and $\mathrm{Ag}$ atoms ${ }^{a}$

\begin{tabular}{ccccc}
\hline & $\begin{array}{c}\text { Au-Acetic } \\
\text { acid }\end{array}$ & $\begin{array}{c}\text { Ag-Acetic } \\
\text { acid }\end{array}$ & $\begin{array}{c}\text { Au- } \\
\text { Ammonia }\end{array}$ & $\begin{array}{c}\text { Ag- } \\
\text { Ammonia }\end{array}$ \\
\hline $\begin{array}{c}\text { Binding energy } \\
\left(\mathrm{kJ} \mathrm{mol}^{-1}\right)\end{array}$ & -9.9 & -1.2 & -46.3 & -25.4 \\
$\begin{array}{c}\text { Net charge of Ag } \\
\text { or Au atom }(\mathrm{e})^{b}\end{array}$ & 0.065 & 0.055 & -0.105 & -0.091 \\
\hline
\end{tabular}

${ }^{a}$ Computed using a Gaussian $03 \mathrm{~W}$ suite ${ }^{44}$ : the LANL2DZ basis sets are used for the $\mathrm{Au}$ and $\mathrm{Ag}$ atoms while the $6-31+\mathrm{G}(\mathrm{d})$ basis sets are used for all atoms of acetic acid and ammonia. ${ }^{b}$ Atomic polar tensor-based net charge. ${ }^{45}$

Gaussian 03W suite at the B3LYP level theory. ${ }^{44,45}$ In this calculation, LANL2DZ basis sets were used for the Au and Ag atoms, while 6-31+G(d) basis sets were used for all atoms of acetic acid and ammonia. As one would expect, both the $\mathrm{Au}$ and $\mathrm{Ag}$ atoms interacted either with the carbonyl oxygen atom of acetic acid or with the nitrogen atom of ammonia. As can be seen in Table 1, all interactions were attractive. On the other hand, when interacting with acetic acid, the net charges of the $\mathrm{Au}$ and $\mathrm{Ag}$ atoms were computed to be 0.065 and $0.055 \mathrm{e}$, respectively. This suggests that acetic acid must act as a stronger electron acceptor when interacting with Au than with $\mathrm{Ag}$. When interacting with ammonia, the net charges of the $\mathrm{Au}$ and $\mathrm{Ag}$ atoms were computed to be -0.105 and $-0.091 \mathrm{e}$, respectively, suggesting that $\mathrm{NH}_{3}$ should act as a stronger electron donor when interacting with $\mathrm{Au}$ than with $\mathrm{Ag}$, in agreement with the prediction deduced from the NC peak shift.

The bandwidth of the NC stretching band in Figures 6(a)$6(d)$ is slightly dependent on the kind of organic vapor, but the shape of the band is mostly symmetric. Considering that 1,4PDI was close-packed on the flat Au substrate, VOCs should have affected more the $\mathrm{Au}$ or $\mathrm{Ag}$ nanoparticles exposed outward rather than the planar Au substrate underneath. The symmetrical band shape would then suggest that the effect given by acetic acid and ammonia onto the $\mathrm{Au}$ or $\mathrm{Ag}$ nanoparticles had been transmitted wholly through 1,4-PDI to the planar Au substrate. Otherwise, we might have seen at least a very asymmetric NC stretching band, specifically a band inclined toward higher frequency in the presence of acetic acid and a band inclined toward lower frequency in the presence of ammonia. Hence, it is presumed that the voltage transmission from $\mathrm{Au}$ or $\mathrm{Ag}$ nanoparticles to the planar $\mathrm{Au}$ is as equally probable to that from the planar $\mathrm{Au}$ to the $\mathrm{Au}$ or $\mathrm{Ag}$ nanoparticles in a nanogap electrode. The ready transmittance must be associated with the conjugation character of 1,4-PDI.

\section{Summary and Conclusion}

The characteristics of two distinct nanogaps formed by a flat Au substrate and an Au or Ag nanoparticle were examined by means of the Raman scattering of 1,4-PDI. Initially, an atomically smooth Au substrate was prepared by a vacuum evaporation method, and then 1,4-PDI was allowed to adsorb thereon via one of its two isocyanide groups. Since the planar Au substrate was SERS inactive, no Raman signal was detected at all. However, upon attaching $60 \mathrm{~nm}$-sized Au or Ag nanoparticles to the pendent isocyanide group, a very intense Raman spectrum was observed, obviously due to the electromagnetic coupling between the localized surface plasmon of $\mathrm{Au}$ or Ag nanoparticle and the surface plasmon polariton of the planar Au substrate. Specifically, a higher Raman signal was observed when Ag nanoparticles were attached onto 1,4PDI, irrespective of the excitation wavelength. Regarding the excitation wavelength dependence, the highest Raman signal was measured at the $632.8 \mathrm{~nm}$ excitation (with the EF on the order of $\sim 10^{3}$ ), followed by the excitation at 568 and 514.5 $\mathrm{nm}$. When Ag nanoparticles were attached to 1,4-PDI, the Raman signal measured at $514.5 \mathrm{~nm}$ excitation was about ten times weaker than that at $632.8 \mathrm{~nm}$ excitation, but when $\mathrm{Au}$ nanoparticles were adsorbed on 1,4-PDI, a signal more than two orders of magnitude weaker was observed as the excitation wavelength was lowered down to $514.5 \mathrm{~nm}$. Much the same observation was made from the 3-D FDTD calculation. This must be due to the different surface plasmon resonances of $\mathrm{Ag}$ or Au nanoparticles, thus suggesting that both the kind of metal and the excitation wavelength have to be taken into account for the highest SERS to occur at the nanogap formed by a planar metal and a spherical metal nanoparticle.

On the other hand, according to the potential-dependent SERS, the NC stretching peaks were determined to vary 
linearly with a slope of 22.3 and $29.6 \mathrm{~cm}^{-1} \mathrm{~V}^{-1}$ for the $\mathrm{Au}-\mathrm{Au}$ and $\mathrm{Ag}-\mathrm{Au}$ nanogap electrodes, respectively, suggesting that the -NC group bound to Ag must experience a stronger Stark effect. Anyhow, the shape of the NC stretching band was independent of the potential variation, suggesting that the voltage applied to the planar Au was transmitted without loss to the $\mathrm{Au}$ or Ag nanoparticles. As another means to distinguish the two types of gaps, we also examined the response of the NC stretching vibration of 1,4-PDI under the flow of two typical VOCs, acetic acid and ammonia. In the presence of acetic acid, the NC stretching peak was blue-shifted by up to 8 and 3 $\mathrm{cm}^{-1}$, respectively, for the $\mathrm{Au}-\mathrm{Au}$ and $\mathrm{Ag}-\mathrm{Au}$ nanogaps, while in the presence of ammonia, the NC stretching peak was redshifted by up to 9 and $4 \mathrm{~cm}^{-1}$, respectively. The amount of blue- and red-shift was larger for the Au-Au nanogap than for the Ag-Au nanogap, suggesting that $\mathrm{Au}$ nanoparticles should be affected more by VOCs than Ag nanoparticles. In conformity with $a b$ initio quantum mechanical calculations, the blue-shift could be understood by assuming that electrons were transferred from $\mathrm{Au}$ or $\mathrm{Ag}$ nanoparticles to the carbonyl oxygen atom of acetic acid, while the red-shift was caused by the electron donation from ammonia to $\mathrm{Au}$ or $\mathrm{Ag}$ nanoparticles, thus raising and lowering the surface potential of metal nanoparticles in the presence of acetic acid and ammonia, respectively. At any rate, the NC stretching band was quite symmetrical even under the flow of VOCs, suggesting that the voltage transmission from $\mathrm{Au}$ or $\mathrm{Ag}$ nanoparticles to the planar Au should be as equally probable to that from the planar Au to the $\mathrm{Au}$ or Ag nanoparticles in a nanogap electrode. The ready transmittance must be associated with the conjugation character of 1,4-PDI.

Acknowledgments. This work was supported by National Research Foundation of Korea Grant funded by the Korean Government (Grant 2011-0001218, 2010-0019204, KRF-2008313-C00390, and 2009-0072467).

\section{References}

1. Chang, R. K.; Furtak, T. E. Surface Enhanced Raman Scattering; Plenum Press: New York, 1982.

2. Moskovits, M. Rev. Mod. Phys. 1985, 57, 783.

3. Nie, S.; Emory, S. R. Science 1997, 275, 1102.

4. Xu, H.; Bjerneld, E. J.; Käll, M.; Börjesson, L. Phys. Rev. Lett. 1999, 83, 4357.

5. Futamata, M.; Maruyama, Y.; Ishikawa, M. Vib. Spectrosc. 2002, $30,17$.

6. Ni, J.; Lipert, R. J.; Dawson, G. B.; Porter, M. D. Anal. Chem. 1999, 71, 4903.

7. Kim, N. H.; Lee, S. J.; Kim, K. Chem. Commun. 2003, 9, 724.

8. Cao, P.; Gu, R.; Tian, Z. Q. Langmuir 2002, 18, 7609.

9. Chu, W.; LeBlanc, R. J.; Williams, C. T.; Kubota, J.; Zaera, F. J. Phys. Chem. B 2003, 107, 14365.

10. Tian, Z. Q.; Ren, B.; Wu, D. Y. J. Phys. Chem. B 2002, 106, 9463.

11. Markel, V. A.; Shalaev, V. M.; Zhang, P.; Huynh W.; Tay L.; Haslett, T. L.; Moskovits, M. Phys. Rev. B 1999, 59, 10903.

12. Bozhelvolnyi, S. I.; Markel, V. A.; Coello, V.; Kim, W.; Shalaev, V. M. Phys. Rev. B 1998, 58, 11441.

13. Michaels, A. M.; Jiang, J.; Brus, L. J. Phys. Chem. B 2000, 104, 11965.

14. Kim, K.; Yoon, J. K. J. Phys. Chem. B 2005, 109, 20731.
15. Yoon, J. K.; Kim, K.; Shin, K. S. J. Phys. Chem. C 2009, 113, 1769.

16. Kim, K.; Lee, H. B.; Yoon, J. K.; Shin, D.; Shin, K. S. J. Phys. Chem. C 2010, 114, 13589.

17. Osawa, M.; Matsuda, N.; Yoshii, K.; Uchida, I. J. Phys. Chem. 1994, 98, 12702.

18. Uetsuki, K.; Verma, P.; Yano, T.; Saito, Y.; Ichimura, T.; Kawata, S. J. Phys. Chem. C 2010, 114, 7515.

19. Liu, S.; Zhao, X.; Li, Y.; Zhao, X.; Chen, M. J. Chem. Phys. 2009, 130, 234509.

20. Hu, X.; Wang, T.; Wang, L.; Dong, S. J. Phys. Chem. C 2007, 111, 6962.

21. Wu, D. Y.; Liu, X. M.; Huang, Y. F.; Ren, B.; Xu, X.; Tian, Z. Q. J. Phys. Chem. C 2009, 113, 18212.

22. Huang, Y. F.; Zhu, H. P.; Liu, G. K.; Wu, D. Y.; Ren, B.; Tian, Z. Q. J. Am. Chem. Soc. 2010, 132, 9244.

23. Robertson, M. J.; Angelici, R. J. Langmuir 1994, 10, 1488.

24. Kim, K.; Shin, D.; Kim, K. L.; Shin, K. S. Phys. Chem. Chem. Phys. 2010, 12, 3747.

25. Shin, D.; Kim, K.; Shin, K. S. ChemPhysChem 2010, 11, 83.

26. Kim, K.; Kim, K. L.; Shin, D.; Lee, J. W.; Shin, K. S. Chem. Commun. 2010, 46, 3753.

27. Lee, P. C.; Meisel, D. J. Phys. Chem. 1982, 86, 3319.

28. Sullivan, D. M. Electromagnetic Simulation Using the FDTD Method; IEEE Press: New York, 2000.

29. Oubre, C.; Nordlander, P.; J. Phys. Chem. B 2004, 108, 17740.

30. Baudhinm, P., Van der Smissen, P., Beauvois, S., Courtoy, P. J., Hayat, M. A., Eds.; Colloidal Gold: Principles, Methods, and Applications; Academic Press: San Diego, 1989; Vol. 2, p 2.

31. Lyon, L. A.; Musick, M. D.; Natan, M. J. Anal. Chem. 1998, 70, 5177.

32. Lyon, L. A.; Pena, D. J.; Natan, M. J. J. Phys. Chem. B 1999, 103, 5826.

33. Hutter, E.; Cha, S.; Liu, J.-F.; Park, J.; Yi, J.; Fendler, J. H.; Roy, D. J. Phys. Chem. B 2001, 105, 8.

34. Han, H. S.; Han, S. W.; Joo, S. W.; Kim, K. Langmuir 1999, 15, 6868.

35. Kim, H. S.; Lee, S. J.; Kim, N. H.; Yoon, J. K.; Park, H. K.; Kim, K. Langmuir 2003, 19, 6701.

36. Ontko, A. C.; Angelici, R. J. Langmuir 1998, 14, 1684.

37. Gole, A.; Sainkar, S. R.; Sastry, M. Chem. Mater. 2000, 12, 1234.

38. Kneipp, K.; Kneipp, H.; Itzkan, I.; Dasari, R. R.; Feld, M. S. Chem. Rev. 1999, 99, 2957.

39. Kim, N. H.; Kim, K. J. Phys. Chem. B 2006, 110, 1837.

40. Oklejas, V.; Sjostrom, C.; Harris, J. M. J. Am. Chem. Soc. 2002, 124,2408

41. Shankar, S. S.; Rai, A.; Ankamwar, B.; Singh, A.; Ahmad, A.; Sastry, M. Nat. Mater. 2004, 3, 482.

42. Shafai, G. S.; Shetty, S.; Krishnamurty, S.; Shah, V.; Kanhere, D. G. J. Chem. Phys. 2007, 126, 014704.

43. Wasileski, S. A.; Koper, M. T. M.; Weaver, M. J. J. Am. Chem. Soc. 2002, 124, 2796.

44. Cioslowski, J. J. Am. Chem. Soc. 1989, 111, 8333.

45. Frisch, M. J.; Trucks, G. W.; Schlegel, H. B.; Scuseria, G. E.; Robb, M. A.; Cheeseman, J. R.; Montgomery, J. A., Jr.; Vreven, T.; Kudin, K. N.; Burant, J. C.; Millam, J. M.; Iyengar, S. S.; Tomasi, J.; Barone, V.; Mennucci, B.; Cossi, M.; Scalmani, G.; Rega, N.; Petersson, G. A.; Nakatsuji, H.; Hada, M.; Ehara, M.; Toyota, K.; Fukuda, R.; Hasegawa, J.; Ishida, M.; Nakajima, T.; Honda, Y.; Kitao, O.; Nakai, H.; Klene, M.; Li, X.; Knox, J. E.; Hratchian, H. P.; Cross, J. B.; Adamo, C.; Jaramillo, J.; Gomperts, R.; Stratmann, R. E.; Yazyev, O.; Austin, A. J.; Cammi, R.; Pomelli, C.; Ochterski, J. W.; Ayala, P. Y.; Morokuma, K.; Voth, G. A.; Salvador, P.; Dannenberg, J. J.; Zakrzewski, V. G.; Dapprich, S.; Daniels, A. D.; Strain, M. C.; Farkas, O.; Malick, D. K.; Rabuck, A. D.; Raghavachari, K.; Foresman, J. B.; Ortiz, J. V.; Cui, Q.; Baboul, A. G.; Clifford, S.; Cioslowski, J.; Stefanov, B. B.; Liu, G.; Liashenko, A.; Piskorz, P.; Komaromi, I.; Martin, R. L.; Fox, D. J.; Keith, T.; Al-Laham, M. A.; Peng, C. Y.; Nanayakkara, A.; Challacombe, M.; Gill, P. M. W.; Johnson, B.; Chen, W.; Wong, M. W.; Gonzalez, C.; Pople, J. A. Gaussian 03W, revision C.01; Gaussian: Wallingford, CT, 2004. 